\title{
OS BENEFÍCIOS DA INTELIGÊNCIA ARTIFICIAL NO MONITORAMENTO DE MÍDIAS SOCIAIS
}

\author{
THE BENEFITS OF ARTIFICIAL INTELLIGENCE IN SOCIAL MEDIA MONITORING
}

\author{
Kaique dos Santos Oliveira' (iD
}

\begin{abstract}
RESUMO
O presente estudo busca apresentar a inteligência artificial (IA) como uma alternativa para agilizar o trabalho de monitoramento dos dados nas mídias sociais. Com o crescente volume de informações gerada pelo usuário, a área ganha mais importância a cada ano e precisa evoluir de acordo com as novas tecnologias disponíveis no mercado. Para isso, foi realizada pesquisa com abordagem qualitativa e revisão bibliográfica sobre o cenário da internet no Brasil, no contexto das mídias sociais e monitoramento, seguida de conceitualização da inteligência artificial nas visões de Norvig (2013) e Lima (2014). Passa-se, então, para o entendimento de algumas áreas dessa ciência e os caminhos para solucionar o problema apresentado. Como resultado, o estudo aponta para a possível utilização das soluções de IA dentro de cada etapa do processo de monitoramento, como polarização, tagueamento e análise de conteúdos em fotos e vídeos. Apresenta também a utilização da inteligência artificial nos três momentos principais do monitoramento das mídias sociais: antes, com o planejamento das ações e análise de concorrência; durante, com o foco no atendimento ao consumidor e identificação de oportunidades de negócio; e, depois, com a geração e análise de relatórios. A utilização desta tecnologia tem como propósito tornar mais rápido e eficiente a estruturação de dados e a tomada de decisão do usuário. A pesquisa traz da IA assuntos como o processo de aprendizagem de máquina, utilização de redes neurais artificiais e deep learning.
\end{abstract}

Palavras-chave: Monitoramento de mídias sociais. Inteligência artificial. Mídias sociais.

\begin{abstract}
This study aims to present artificial intelligence (Al) as an alternative to make the process of social media monitoring faster. With the growing volume of information generated by the user, the area gains more importance every year and needs to evolve according to the new technologies available on the market. So, research was carried out with a qualitative approach and bibliographic review on the internet scenario in Brazil, in the context of social media and monitoring, followed by conceptualization of artificial intelligence in the views of Norvig (2013) and Lima (2014). Then, we move on to the understanding of some areas of this science and the ways to solve the problem presented. As result, the study points to the possible uses of Al solutions within each stage of the monitoring process, such as polarization, tagging and content analysis in photos and videos. It also presents the use of artificial intelligence in the three main moments of monitoring social media: before, with action planning and competition analysis; during, with a focus on customer service and identification of business opportunities;
\end{abstract}

1 MBA - Análise de Inteligência de Negócio - Instituto de Gestão em Tecnologia da Informação, IGTI.

Professor orientador: Esp. Paul Robert Bergami

Autor Correspondente: Kaique dos Santos Oliveira

E-mail: kaique.oliveira@icloud.com

Recebido em 17 de Jul de 2020 | Aceito em 18 de Fev de 2021. 
and after with the generation and analysis of reports. The use of this technology aims to make data structuring and user decision making faster and more efficient. The research brings from Al subjects such as the machine learning process, the use of artificial neural networks and deep learning.

Keywords: Social media monitoring. Artificial intelligence. Social media.

\section{Introdução}

Segundo dados divulgados pela ComScore no estudo de tendências para 2017, o Brasil possui mais de 97 milhões de usuários únicos conectados às mídias sociais. Este número inclui tantos os usuários conectados no desktop, quanto os usuários conectados no mobile. Para quem trabalha como analista de mídias sociais, focado no monitoramento dessas plataformas, isso representa um volume gigantesco de informações que trafegam diariamente pela internet.

Silva (2012) define o monitoramento de mídias sociais como o processo de estruturação de dados com um propósito claro relacionado ao negócio ou com algum outro objetivo. Silva (2012) também explica que o processo de monitoramento de mídias sociais é composto por diversas etapas, como coleta, armazenamento, classificação, adição de informações e análise de menções online públicas.

Dentro deste cenário, com grande volume de dados para serem estruturados para a tomada de decisão em um negócio, o profissional responsável por esta tarefa compromete a maior parte do tempo na classificação dos dados não-estruturados, sem ter a oportunidade de fazer novos tipos de cruzamento e, principalmente, automatizar a demanda manual de estruturação dos dados.

Em sua publicação mais recente sobre monitoramento de mídias sociais, Silva (2016) afirma que a partir de 2013 os profissionais chamados de analistas de mídias sociais, antes responsáveis por diversas atividades além do monitoramento dessas plataformas, ganharam mais espaço nas empresas e em 2015 a atividade de monitorar mídias sociais passou a representar cerca de $59 \%$ do seu trabaIho. Isso significa que esta área ganha mais importância a cada ano e precisa evoluir de acordo com as novas tecnologias disponíveis no mercado.

Dentro deste universo, em que o assunto mais discutido é o volume de dados produzido nas mídias sociais e como analisá-lo, faz-se necessário estudar soluções que contribuam com a varredura dessas informações e, principalmente, com a mineração do que é relevante. A proposta deste estudo é trazer como alternativa para essa problemática a inteligência artificial (IA).
Em uma das definições apresentadas por Norvig (2013), a IA é apresentada como a arte de criar máquinas que executam funções que atualmente exigem a inteligência de um ser humano. O objetivo deste estudo é, utilizando bibliografia especializada sobre o tema, orientar sobre os principais benefícios desta tecnologia no monitoramento de mídias sociais, com foco na utilização desta solução no processo de estruturação de dados e na geração de insights para a tomada de decisão do usuário.

\section{Metodologia}

A pesquisa realizada é de natureza básica e abordagem qualitativa, baseada em uma revisão bibliográfica que teve como objetivo buscar orientações que refletissem os benefícios da inteligência artificial no trabalho de monitoramento de mídias sociais.

Inicialmente, a revisão bibliográfica foi baseada no cenário da internet no Brasil, no contexto das mídias sociais e seu monitoramento. Vale destacar que o processo de monitoramento pode ser adaptado para as diversas mídias sociais, sendo amplamente utilizado com as redes mais populares como Facebook, Twitter e YouTube.

Após essa introdução, inicia-se a apresentação dos conceitos de inteligência artificial e os principais benefícios da aprendizagem de máquina. A conclusão do trabalho traz uma orientação com as formas estudadas de utilização da inteligência artificial na análise de dados no processo de monitoramento das mídias sociais.

Para Gil (2008), o uso da abordagem qualitativa propicia o aprofundamento da investigação das questões relacionadas ao fenômeno em estudo e das suas relações, mediante a máxima valorização do contato direto com a situação estudada, buscando-se o que era comum, mas permanecendo, entretanto, aberta para perceber a individualidade e os significados múltiplos.

\section{Revisão de Literatura}

O estudo começa com a contextualização de monitoramento de mídias sociais, baseado nos artigos do pesquisador Tarcízio Silva, e em um estudo de tendências 
do mercado digital para 2017, divulgado pela ComScore. Após o entendimento deste processo de coleta e tratamento de informações coletadas das mídias sociais, inicia-se a conceitualização da inteligência artificial, com base nas visões dos teóricos Peter Norvig (2013) e Isaías Lima (2014). Peter Norvig atualmente é diretor de pesquisa do Google Inc. e foi o diretor responsável pelos algoritmos de busca do núcleo da web de 2002 até 2005. Além disso, ele é membro efetivo da Associação Americana de Inteligência Artificial e supervisionou a pesquisa e desenvolvimento da robótica e da inteligência artificial para a NASA. Isaías Lima, também inspirado nas teorias de Norvig, além de se dedicar a carreira acadêmica, como professor Associado na Universidade de Itajubá, ele realiza pesquisas relacionadas ao desenvolvimento e aplicações de inteligência artificial em sistemas de controle e automação. Ambos os autores possuem uma vasta experiência no tema. Por este motivo, eles foram selecionados para a construção de toda a base sobre IA. Após essa definição, o estudo passa para o entendimento de algumas áreas dessa ciência e os possíveis caminhos que irão de encontro com a solução do problema de pesquisa.

\subsection{Monitoramento de mídias sociais}

O monitoramento de mídias sociais é o processo de transformar dados em conhecimento (Silva, 2012). O termo monitoramento contempla um contexto que inclui tipos de serviços, diferentes ferramentas, profissionais e diversos recursos necessários para o planejamento e aplicação de uma estratégia focada em comunicação digital.

Coleta, armazenamento, classificação, categorização, adição de informações e análise de menções online públicas a determinado(s) termo(s) previamente definido(s) e seus emissores, com os objetivos de: (a) identificar e analisar reações, sentimentos e desejos relativos a produtos, entidades e campanhas; (b) conhecer melhor os públicos pertinentes; e (c) realizar ações reativas e proativas para alcançar os objetivos da organização ou pessoa (Silva, 2012).

\subsubsection{Análise da informação}

A análise da informação começa com o processo de organização da informação (OI) que, no monitoramento de mídias sociais, tem início pelo levantamento de requisitos, também chamado de briefing, que inclui um resumo sobre o mercado a ser analisado, cliente, concorrentes, influenciadores e todo e qualquer dado necessário para o início do projeto. (Araújo \& Steimer, 2016). "Pode contribuir ainda na definição dos objetivos do projeto (escopo de coleta, volume de menções analisadas, critérios de amostragem e experiência de analistas) relativos ao Planejamento de Classificação, seja no Plano de Polarização ou no Plano de Tagueamento" (Araújo \& Steimer, 2016).

\subsection{Inteligência artificial}

Em uma das definições apresentadas por Norvig (2013), a inteligência artificial (IA) é apresentada como a arte de criar máquinas que executam funções que atualmente exigem a inteligência de um ser humano. A inteligência artificial é considerada como um dos campos mais recentes em ciências e engenharia. Este trabalho começou após a Segunda Guerra Mundial e seu nome foi determinado em 1956.

Atualmente, a IA abrange uma enorme variedade de subcampos, do geral (aprendizagem e percepção) até tarefas específicas, como jogos de xadrez, demonstração de teoremas matemáticos, criação de poesia, direção de um carro em estrada movimentada e diagnóstico de doenças. A IA é relevante para qualquer tarefa intelectual; é verdadeiramente um campo universal" (Russel \& Norvig, 2013).

\subsubsection{Aprendizado de máquina}

Dentro das linhas de pesquisa que incluem a aplicação das técnicas de inteligência artificial existe o aprendizado de máquina (Machine Learning). Norvig (2013) define este termo como a capacidade de uma máquina aperfeiçoar seu comportamento a partir do estudo de suas próprias experiências.

\subsubsection{Redes neurais artificiais}

Dentro do contexto de aprendizado de máquina temos as redes neurais artificiais (RNAs), também conhecidas como modelos conexionistas, que são caracterizadas como modelos computacionais capazes de adaptar, aprender, generalizar, agrupar e organizar dados dentro de uma estrutura de processamento paralelo (Norvig, 2013). Isaías Lima, autor que também teve contato com os estudos de Norvig, complementa da seguinte forma:

Uma rede neural é formada por um conjunto de unidades básicas de processamento que se comunicam enviando informações uma para a outra por meio de determinadas conexões. O componente elementar desse modelo são as unidades de processamento, também chamadas nós, neurônios ou células. Essa unidade de processamento é um modelo matemático que possui inspiração no modelo biológico de um neurônio (Lima, 2014). 


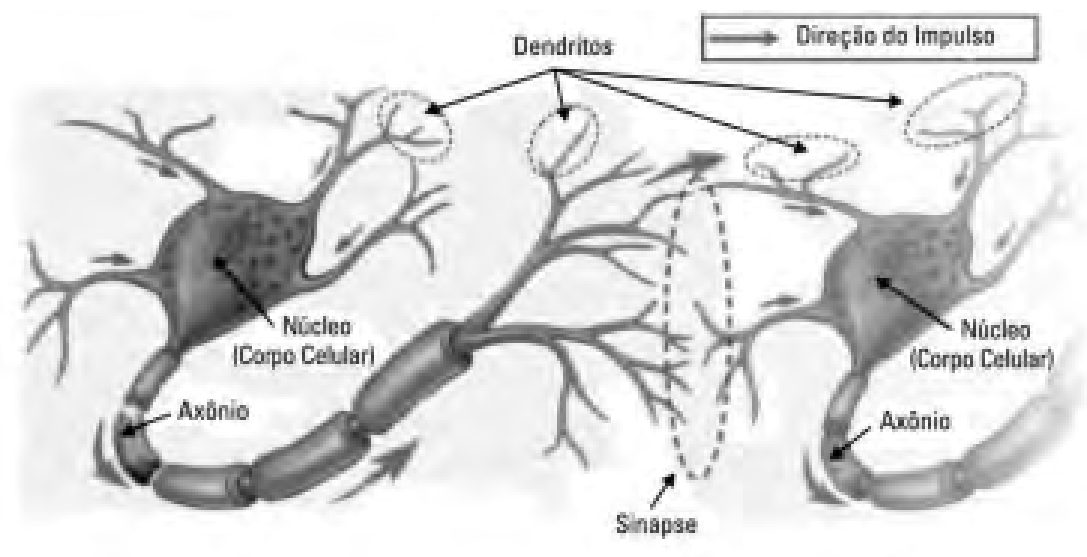

Figura 1. Ilustração de um neurônio biológico.

Fonte: Do acervo de conteúdo livre Wikimedia Foundation.

Uma RNA é composta por uma camada de entrada, que recebe os estímulos do modelo, e uma camada de saída, que é responsável pela resposta. Algumas redes podem ser constituídas por uma ou mais camadas internas, também nomeadas como camadas ocultas ou escondidas.

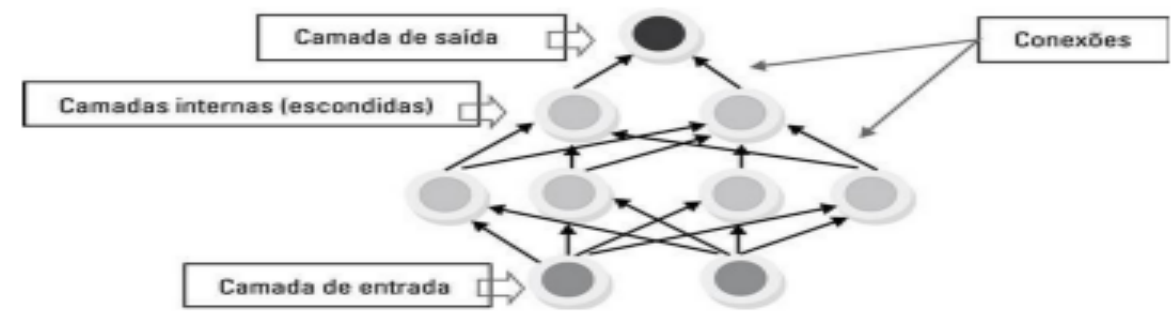

\section{FIGURA 3.7 \\ Representação de uma RNA típica.}

Figura 2. Representação de uma RNA típica.

Fonte: De “Inteligência Artificial” de I. Lima, 2014, Campus.

O modelo matemático proposto por McCulloh e Pitts (1943) que simula o comportamento de um neurônio biológico está representado na próxima figura. Cada informação de entrada é multiplicada por um número ou peso, que logo após é somada em um nó ou ponto de soma. Se o resultado for exceder determinado limiar delimitado por uma função chamada ativação, é gerada uma resposta na saída do modelo. A capacidade computacional de uma RNA está presente nas conexões entre os elementos processadores. Dentro dos pesos que ponderam cada conexão são armazenadas as informações que a rede assimilou.

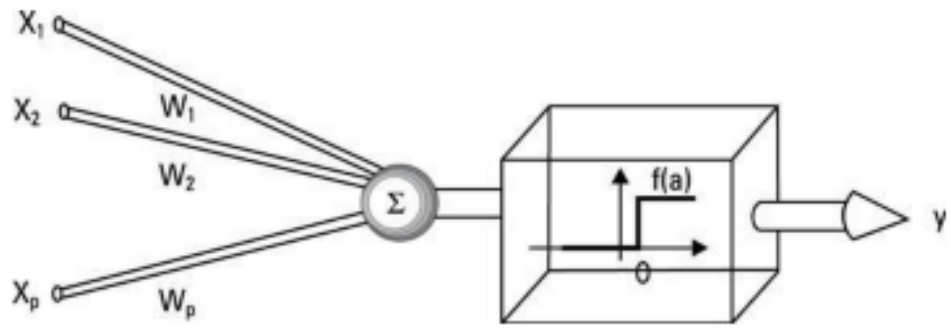

Figura 3. Modelo Matemático básico de um neurônio

Fonte: Tafner et al, 1996. 
Em resumo, a rede neural é dinâmica e autoadaptativa, pois os elementos de processamento possuem a capacidade de autoajuste. Autoadaptativa porque ela é capaz de modificar suas respostas com base em suas experiências em determinadas situações e dinâmica porque pode adaptar-se a diferentes condições, com o objetivo de dar a resposta satisfatória de acordo com as novas entradas ou estímulos.

\subsubsection{Deep learning}

Norvig (2013) apresenta esta aplicação como uma forma de resolver problemas mais complexos como reconhecimento de imagens, reconhecimento de voz, processamento de linguagem natural e entre outras situações que necessitam de um poder maior de análise.

Deep learning é um algoritmo que pode ser aplicado em RNAs para a resolução de problemas mais complexos. Basicamente, este algoritmo constrói as camadas ocultas, apresentadas anteriormente na figura 3, e aumenta a capacidade de interpretação da rede neural.

Os pesquisadores lan Goodfellow, Yoshua Bengio e Aaron Courville, em um artigo publicado pela MIT Press em 2016, definem deep learning da seguinte forma:

Modern deep learning provides a very powerful framework for supervised learning. By adding more layers and more units within a layer, a deep network can represent functions of increasing complexity. Most tasks that consist of mapping an input vector to an output vector, and that are easy for a person to do rapidly, can be accomplished via deep learning, given sufficiently large models and sufficiently large datasets of labeled training examples. Other tasks, that can not be described as associating one vector to another, or that are difficult enough that a person would require time to think and reflect in order to accomplish the task, remain beyond the scope of deep learning for now. If we draw a graph showing how these concepts are built on top of each other, the graph is deep, with many layers. For this reason, we call this approach to Al deep learning (Goodfellow, Bengio \& Courville, 2016).

\section{Apresentação da Pesquisa}

A pesquisa que teve como natureza básica e abordagem qualitativa foi baseada em uma revisão bibliográfica que teve como objetivo buscar orientações que refletissem os benefícios da inteligência artificial no trabalho de monitoramento de mídias sociais. Em um primeiro momento foi necessário fazer uma imersão no universo de monitora- mento de mídias sociais, baseado nos artigos publicados por Tarcízio Silva, para o entendimento dos processos desta atividade e depois compreender as soluções disponíveis nas aplicações de inteligência artificial. $O$ conceito de IA foi fundamentado por Peter Norvig e complementado pelas publicações Inteligência Artificial (Russel \& Norvig, 2013) e Deep Learning (Mit Press, 2016).

\subsection{O propósito do monitoramento de mídias sociais}

Conforme contextualizado neste artigo, de acordo com Tarcízio Silva, o monitoramento de mídias sociais é uma atividade que contempla diversas tarefas como: coleta e armazenamento de dados, classificação e categorização de menções online públicas e análise das informações obtidas no final do processo. O objetivo desta atividade, independente da etapa de aplicação, é gerar informação e conhecimento que suporte tomadas de decisões assertivas para os profissionais de marketing que dependem cada vez mais desses dados para o desenvolvimento, crescimento e sustentação de marcas no mercado. Quanto mais usuários conectados às mídias sociais, mais informação será gerada e mais os profissionais de marketing dependerão da atividade de monitoramento de mídias sociais para o seu negócio. Atualmente são mais de 97 milhões de usuários únicos conectados às mídias sociais, de acordo com a pesquisa divulgada pela ComScore no relatório de tendências para 2017. De acordo com Tarcízio Silva, desde 2015 a atividade de monitorar mídias sociais passou a representar mais de $59 \%$ do tempo de trabalho de um analista de mídias sociais, que antes tinha diversas outras tarefas além do monitoramento no seu escopo. Com o aumento do volume de dados e maior necessidade de profissionais especializados em monitoramento de mídias sociais, é normal que as empresas busquem automatizar a mão de obra e dedicar o maior esforço na análise das informações. É por este motivo que este artigo apresenta como solução para este cenário a aplicação da inteligência artificial.

\subsubsection{Aplicações do monitoramento de mídias sociais}

O monitoramento de mídias sociais possui diversas aplicações. Tarcízio Silva apresenta três das principais, divididas em etapas que ele categoriza como antes, durante e depois: 
Tabela 1. Comparativo das aplicações de monitoramento de mídias sociais

\begin{tabular}{|c|c|}
\hline Tempo & Aplicação \\
\hline Antes & $\begin{array}{c}\text { O antes geralmente contempla a etapa de planejamento e pesquisa } \\
\text { para um projeto de comunicação digital. A partir da seleção de canais, } \\
\text { análise de assuntos, identificação de influenciadores, monitoramento de } \\
\text { concorrentes e outras aplicações o profissional de marketing pode tomar } \\
\text { decisões mais assertivas com base em dados. }\end{array}$ \\
\hline Durante & $\begin{array}{l}\text { Chamada de etapa de gestão e manutenção, os esforços são focados no } \\
\text { Serviço de Atendimento ao Consumidor (SAC). Ou seja, interação direta } \\
\text { com os consumidores a partir das mídias sociais, identificação de opor- } \\
\text { tunidades de negócio e intervenção no processo de decisão de compra. }\end{array}$ \\
\hline Depois & $\begin{array}{c}\text { Ao chegar no final do ciclo, inicia-se a etapa de avaliação e mensuração. } \\
\text { Nesta fase é necessário analisar os resultados obtidos e validar se os } \\
\text { objetivos planejados foram alcançados. }\end{array}$ \\
\hline
\end{tabular}

Fonte: De “Monitoramento e pesquisa em mídias sociais: metodologias, aplicações e inovações”, de T. Silva \& M. Stabile, 2016.

\subsubsection{Atividades primárias do monitoramento de mídias sociais}

Uma das principais atividades dentro do monitoramento de mídias sociais é o planejamento de classificação, citado por Tarcízio Silva, que visa construir um modelo de organização das informações não estruturadas em linguagem natural, publicadas por usuários de mídias sociais. O planejamento orienta a execução de duas atividades primárias do monitoramento do projeto: a) Polarização: Atribuição de sentimento a informação publicada pelo usuário nas mídias sociais, com base na lista de termos monitorados. b) Tagueamento: Atribuição de tags ao conteúdo, com o objetivo de identificar de forma estruturada os assuntos contidos na publicação feita por cada usuário. A atividade de polarização e tagueamento precisa ser executada com base em algumas garantias, que o autor apresenta como: a) Garantia literária e organizacional: O conhecimento do cenário do cliente, principalmente sobre o seu negócio, e os objetivos da marca. b) Garantia do usuário e cultural: O conhecimento sobre os usuários que interagem com a marca, o comportamento deste consumidor.

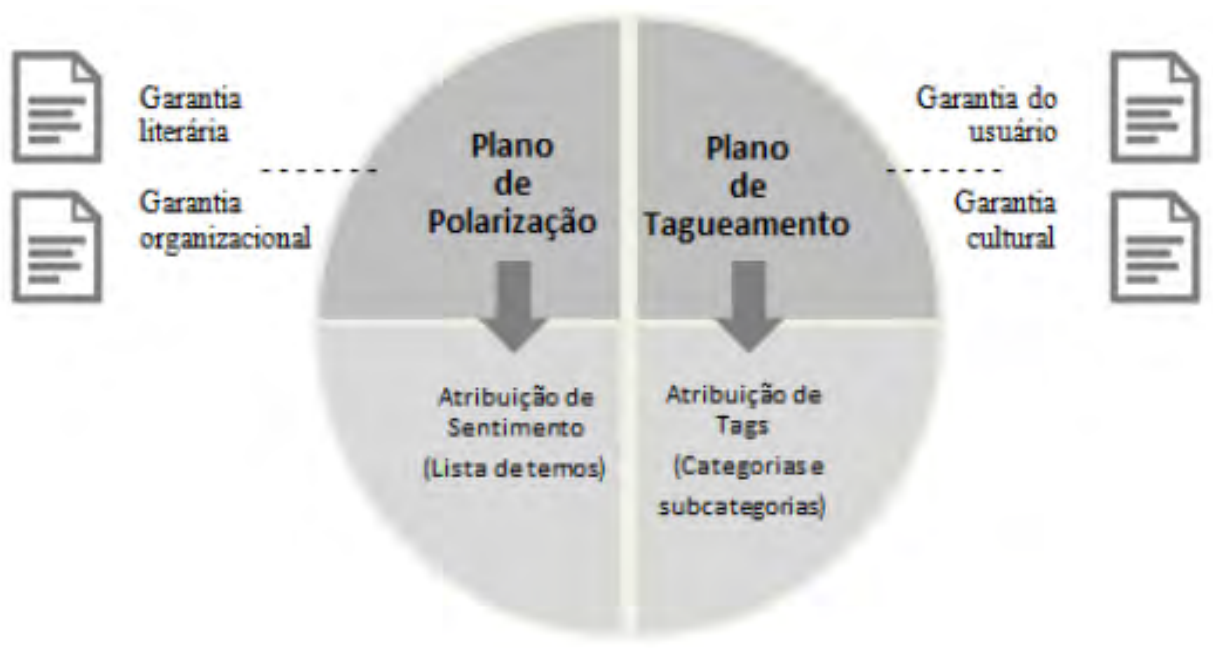

Figura 4. Garantias no planejamento de classificação

Fonte: De “Monitoramento e pesquisa em mídias sociais: metodologias, aplicações e inovações", de T. Silva \& M.Stabile, 2016, São Paulo, SP: Uva limão. 


\subsection{Soluções de inteligência artificial}

Dentro das linhas de pesquisa que incluem a aplicação das técnicas de inteligência artificial existe o aprendizado de máquina (Machine Learning). Isaías Lima explica que esta linha de pesquisa foca em soluções que utilizam de sistemas e métodos computacionais para desenvolver sistemas capazes de adquirir conhecimento sem a necessidade de um humano.

De acordo com Peter Norvig (2013) existem três principais tipos de aprendizagem: a) Aprendizado supervisionado: este método tem como princípio a minimização do erro entre o resultado desejado e o resultado alcançado pelo sistema. Baseado na diferença dos resultados apresentados, o sistema é ajustado a cada determinação de um padrão de treinamento. $O$ processo pode ser repetido diversas vezes até que o conhecimento seja absorvido. Norvig (2013) exemplifica este tipo de aprendizagem no caso de um robô receber estímulos a partir de imagens e identificadores, com o nome do objeto exibido para o sistema. b) Aprendizado não supervisionado: neste método o conhecimento é gerado com base apenas nos estímulos de entrada que são disponibilizados para o sistema, sem nenhum feedback de humanos. Norvig (2013) exemplifica este tipo de aprendizagem sem feedback na situação de um robô de análise de trânsito que consegue identificar um tráfego intenso ou bom sem a necessidade de um tutor. c) Aprendizado por reforço: neste método o conhecimento é gerado com base em feedbacks positivos ou negativos de um humano. Norvig exemplifica este tipo de aprendizagem com um robô em um jogo de xadrez que ao receber pontos compreende que fez uma coisa certa.

Existem diversas abordagens da inteligência artificial dentro do aprendizado de máquina. $\mathrm{O}$ autor Isaías Lima apresenta as seguintes abordagens: a) Simbólica: Essa abordagem trabalha com problemas bem definidos, como um planejamento de tarefas. Em resumo, esta forma tem como objetivo analisar comportamentos inteligentes com base em aspectos psicológicos e processos algorítmicos. b) Conexionista: Essa abordagem trata de problemas imprecisos, mas que podem ser identificamos a partir de exemplos, como o reconhecimento de caligrafia. Também conhecida como biológica ou ascendente, esta abordagem prioriza o modelo de funcionamento do cérebro, dos neurônios e das conexões neurais. c) Evolucionária: Baseada na teoria evolutiva de Darwin, a hipótese trabalha com a possibilidade de modelar sistemas, denominados inteligentes, simulando a evolução da população que carrega genes com informações que contribuem com a solução de problemas. d) Conjuntos difusos e aproximados:
Os conjuntos difusos são indicados para interpretações linguísticas que tornam mais fácil as representações de modelos matemáticos resultantes. Os conjuntos aproximados são indicadores para o tratamento de informações que não são consistentes. A combinação de diferentes abordagens é denominada de modelagem híbrida. Neste caso, utiliza-se de diferentes técnicas de IA para obter a solução adequada ao problema do projeto.

Esta pesquisa aprofunda-se especificamente na abordagem conexionista, a partir do estudo das redes neurais artificiais. O motivo do aprofundamento nesta abordagem é que, conforme apresentado na contextualização de monitoramento de mídias sociais, os dados coletados não são estruturados e geralmente necessita-se da atuação de um humano para a classificação das menções. E, neste caso, o objetivo desta abordagem é construir um sistema com inteligência suficiente para realizar o trabaIho operacional ou, até mesmo, a análise dos dados que são obtidos a partir da estruturação dos dados coletados das mídias sociais.

\subsubsection{Utilização de redes neurais artificiais}

Após a decisão da utilização do modelo de redes neurais artificiais, é necessário pensar no formato da rede que será utilizado. Norvig (2013) apresenta duas formas fundamentalmente distintas para fazer isso. São elas: a) Alimentação para frente: A primeira delas é a rede com alimentação para frente que tem conexões em uma única direção. Ou seja, este é um modelo simples de entrada e saída que não envolve uma aprendizagem complexa de máquina. b) Rede recorrente: $O$ segundo formato é chamado de rede recorrente, considerado pelo autor o tipo mais interessante e desejado por todos, pois alimenta suas saídas de volta às suas próprias entradas. Basicamente, este segundo formato é o que mais se aproxima do funcionamento do cérebro humano.

Isaías Lima apresenta três processos que colaboram com o entendimento da adaptabilidade dos sistemas neurais: a) Aprendizado: Aprendizado é o poder de autoadaptação da rede com auxílio dos elementos de processamento. Durante o processo de aprendizado as conexões ponderadas passam por uma etapa de ajuste que tem como objetivo encontrar os resultados desejados. A partir do processo de treinamento, o sistema faz o ajuste entre as conexões ponderadas e os elementos de processamento. Além disso, conforme apresentado, o processo de aprendizado pode acontecer de duas formas diferentes: aprendizado supervisionado ou não supervisionado. b) Treinamento: Treinamento é a forma que a rede neural aprende, 
com base no modelo matemático que simula o comportamento de um neurônio biológico. Esta fase consiste na exposição do sistema a um conjunto de informações com o intuito de encontrar um estado de auto-organização particular. c) Generalização: Generalização é a habilidade que a rede neural possui ao responder de forma adequada a padrões que não fizeram parte do conjunto de informações do treinamento. Esta função é extremamente importante, pois faz com que o sistema encontre soluções e respostas, mesmo quando as informações de entrada não estão completas ou estão imprecisas.

Norvig (2013) e Lima (2014) apresentam a utilização de redes neurais artificiais como uma forma de criar sistemas capazes de executar tarefas que antes só eram feitas por humanos. Para contrapor esta visão, o artigo Building Machines That Learn and Think Like People, publicado por pesquisadores da New York University, MIT e Harvard University, mostra que a inteligência artificial, apesar de ter evoluído muito ao longo dos anos, ainda precisará de muitos recursos para alcançar a forma de pensar e agir do ser humano.

\begin{abstract}
"When comparing people and the current best algorithms in Al and machine learning, people learn from less data and generalize in richer and more exible ways. Even for relatively simple concepts such as han$d$ written characters, people need to see just one or a few examples of a new concept before being able to recognize new examples, generate new examples, and generate new concepts based on related ones." Building Machines That Learn and Think Like People.
\end{abstract}

Por outro lado, Dr. Shoumen Datta (2016), pesquisador do MIT, defende que inteligência artificial não é uma utopia, pois os sistemas evoluem cada vez mais e, em determinados momentos, pode tomar uma decisão mais assertiva que humanos. Datta se apresenta como um otimista da IA e diz: "The questions about "intelligence" in Al persists.
Even more questions failed to answer if the I in Al is
true intelligence or some advanced form of multi-lev-
el dynamics with/without a higher order of struc-
tured complex networks or (even better) temporal
networks. The semantics depends on and is colored
by one's view of systems or interpretation of what
is intelligence, what constitutes proof of intelli-
gence and the nature of complexity." (Datta, 2016).

\subsubsection{Evolução de redes neurais artificiais com deep learning}

Os pesquisadores responsáveis pelo artigo Building Machines That Learn and Think Like People acreditam que conceitos como deep learning e outros algoritmos podem chegar mais próximo de aprender e pensar como humanos caso eles consigam incorporar ingredientes psicológicos que não estejam apenas em papéis, descritos detalhadamente como atualmente é necessário na maioria das formas de aprendizagem de máquina. Com o objetivo de colaborar com o avanço das pesquisas relacionadas à inteligência artificial, os pesquisadores apontam alguns ingredientes que eles consideram essenciais para a evolução das máquinas até que elas tenham um aprendizado e pensamento mais parecido com o dos humanos. São eles: a) Compreensão do cenário como um todo: os pesquisadores explicam que as máquinas possuem a capacidade de reconhecimento de objetivos, mas elas precisam também ser treinadas para o reconhecimento do contexto de onde aquele objeto se encontra. Diferente das máquinas, os humanos têm maior facilidade de interpretar este tipo de problema, até mesmo por poder compreender o pensamento de outros humanos, caso eles estejam no mesmo cenário. Para os humanos, esse reconhecimento acontece sem muitos estímulos, diferente das máquinas que ainda precisam ser treinadas em diversos cenários para reconhecerem fragmentos deste problema, sem a facilidade de olhar para o cenário como um todo. b) Agentes autônomos: neste tópico os pesquisadores discutem sobre a dificuldade de treinar um sistema com todas as possíveis situações que podem acontecer. Como exemplo, eles citam a capacidade de humano de entender uma nova forma de cumprimento em uma interação, sem a necessidade de muitos estímulos. Diferente de uma máquina que precisa de diversos estímulos e situações para compreender e copiar uma caligrafia, por exemplo. c) Direção autônoma: sistemas autônomos inteligentes precisam de uma psicologia intuitiva para serem considerados realmente efetivos. Além de detectar pedestres atravessando as ruas, os sistemas precisam ser capazes de detectar a intuição do comportamento daquele pedestre naquele momento. Identificar, por exemplo, se o pedestre realmente tem a intuição de atravessar a rua, mesmo compreendendo que não é seguro, ou se aquele pedestre está prestando atenção no trânsito. d) Design e criatividade: A capacidade criativa geralmente está relacionada à humanos, pois, além de combinar diferentes elementos para criar algo novo, faz com que esses elementos tenham algum tipo de ligação, diferente do que máquinas atualmente são capazes de fazer. Em resumo, os pesquisadores acreditam que, para a evolução acontecer, os estudos de inteligência 
artificial precisam avançar a ponto de fazer com que as máquinas dependam cada vez menos de dados de treinamento para executarem as atividades e também poderem compreender um contexto maior.

Do outro lado, uma pesquisa desenvolvida por Patrick Oliver Glauner e Dr. Radu State (2016), na Universidade de Luxemburgo, provou que é possível obter alguns resultados na aplicação da técnica de deep learning, como a capacidade de aprendizado complexo a partir de hierarquias de informação, velocidade de aprendizagem e capacidade de previsão. Na figura a seguir está representado, de forma gráfica, o aprendizado por hierarquia de informação, baseado na interpretação de uma imagem:

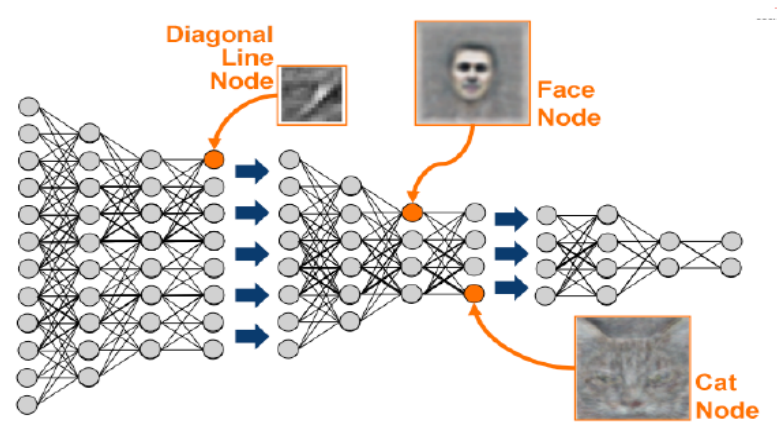

Deep neural network layers learning complex feature hierarchies

Figura 5. Deep neural network layers learning complex feature hierarchies

Fonte: De "Deep learning concepts from theory to practice. Security and Trust Ju", de P. O. Glauner \& R. State, 2016, University of Luxembourg

\section{Discussão dos Resultados}

Conforme apresentado na sessão anterior, temos opções de aplicação da inteligência artificial que podem ser benéficas para o trabalho de monitoramento de mídias digitais.

Para representar melhor a orientação dos benefícios dessa aplicação, será necessário resgatar as premissas da atividade, pois é possível aplicar a tecnologia em diferentes momentos do monitoramento. Os tópicos a seguir apresentam esses momentos e explicam como a IA pode ser aplicada. Como já foi explicado, existem duas atividades primárias na atividade de monitoramento: polarização e tagueamento.

\subsection{Polarização}

Para polarização é necessário identificar o sentimento da menção do usuário que geralmente é dividido entre positivo, negativo e neutro. Essa é uma das atividades que necessitaria da interpretação de humano, para compreender quando uma citação tem uma conotação ruim ou não. Para este problema, recomenda-se a aplicação das redes neurais artificiais que, de acordo com Norvig, tendem a representar o cérebro biológico e que, a partir de uma aprendizagem por reforço, poderá aprender a reconhecer a polaridade das menções de forma assertiva. É esperado que alguns tipos de menções necessitem de maior treinamento que outras, como aquelas que possuem algum tom de ironia. Porém, ao retornar um feedback para o sistema ele irá aprender que determinados tipos de menções podem conter ironia e devem ser melhor interpretadas. Com essa aplicação será possível identificar a saudabilidade de uma marca com base nos sentimentos dos usuários que estão nas mídias sociais.

\subsection{Tagueamento}

O tagueamento, na prática, é o agrupamento de menções em determinados temas ou assuntos. Neste caso, a rede neural artificial também pode ser aplicada, mas o processo de maior importância neste caso será a habilidade de generalização de uma RNA, apresentada por Isaías Lima como a forma de dar respostas adequadas sem a necessidade de ter um conjunto de informações prévio no treinamento da rede. Basicamente, nesta aplicação ela irá reconhecer padrões e agrupá-los ao longo da análise baseando-se em um aprendizado não-supervisionado, muito utilizado neste tipo de análise chamada de competitiva. Com essa aplicação, será fácil identificar quando um determinado assunto estiver em alta nas publicações feitas pelos usuários nas mídias sociais.

\subsection{Tipo de conteúdo}

Em qualquer uma das atividades primárias citadas, existe a variação do tipo de conteúdo que será analisado. Geralmente são fotos e textos publicados por usuários nas mídias sociais. A análise de imagens é considerada um problema complexo que necessita de algoritmos de deep learning, conforme apresentado pelos pesquisadores Patrick Oliver Glauner e Dr. Radu State que utilizaram da capacidade de aprendizado complexo a partir de hierarquias de informação. Com a aplicação destes algoritmos nas redes neurais artificiais será possível reconhecer imagens de objetos, marcas, produtos e até pessoas. Para 
realizar esse tipo de atividade com sucesso, será necessário a aplicação do aprendizado supervisionado, que tem como princípio minimizar o erro entre o resultado desejado e o resultado alcançado. Ao falar de reconhecimento de imagens é importante lembrar que este recurso ainda possui limitações se comparada com a inteligência humana, como foi apresentado pelos pesquisadores no artigo Building Machines That Learn and Think Like People. Com essa aplicação será possível responder a perguntas como: quais são os produtos da minha marca que mais aparecem nas fotos publicadas pelos usuários nas mídias sociais?

\subsection{Aplicações de monitoramento de mídias sociais}

A utilização da inteligência artificial também pode ser dividida entre as três principais aplicações do monitoramento de mídias sociais, apresentadas anteriormente na pesquisa por Tarcízio Silva.

Tabela 2. Soluções de inteligência artificial em diferentes aplicações do monitoramento de mídias sociais

\begin{tabular}{|c|c|}
\hline Tempo & Aplicação \\
\hline Antes & $\begin{array}{c}\text { O antes, que contempla a fase de planejamento e análise da con- } \\
\text { corrência, pode ser executado por RNAs a partir de um aprendizado } \\
\text { não-supervisionado. Desta forma será garantido a geração de insumos } \\
\text { a partir da habilidade de generalização da rede. Com esta aplicação o } \\
\text { profissional de marketing poderá observar oportunidades e criar estra- } \\
\text { tégias com base em insights que possivelmente não seriam detectados } \\
\text { por humanos na mesma velocidade e clareza. }\end{array}$ \\
\hline Durante & $\begin{array}{l}\text { O durante, que requer maior esforço no Serviço de Atendimento ao } \\
\text { Consumidor, pode ser feito parcialmente por uma máquina a partir de } \\
\text { uma árvore de decisão, que contém um conjunto de perguntas e res- } \\
\text { postas, ou a partir de uma RNA que pode ser treinada por um aprendi- } \\
\text { zado por esforço. Assim, a cada resposta e feedback, mais assertivo será } \\
\text { o resultado e menor será a necessidade de um atendente no processo. }\end{array}$ \\
\hline Depois & $\begin{array}{l}\text { A fase final tem relação direta com a geração e análise de relatórios. } \\
\text { Nesta etapa também é possível utilizar de RNAs para a interpretação } \\
\text { dos gráficos, criação de alertas com base em generalização e interação } \\
\text { a partir de linguagem natural. Desta forma seria possível questionar os } \\
\text { dados a partir de textos corridos, por exemplo, e criar análises de forma } \\
\text { dinâmica, pois o algoritmo de deep learning iria ser útil. }\end{array}$ \\
\hline
\end{tabular}

Fonte: Utilização do quadro 01 para apresentar os resultados da pesquisa de uma forma organizada.

\section{Considerações Finais}

Ao final da pesquisa foi possível compreender que a inteligência artificial pode ser aplicada em diversas etapas do processo de monitoramento de mídias sociais. Conforme resgatado na seção cinco, o monitoramento de mídias sociais possuí duas atividades primárias, nomeadas como polarização e tagueamento. Nestas duas etapas, a inteligência artificial pode atuar como uma facilitadora no processo de análise e mineração dos dados. Quanto menos tempo for investido no processo manual, maior será o investimento de tempo nas análises mais profundas que necessitam de um humano.
Além dos benefícios da aplicação da inteligência artificial nas atividades primárias do monitoramento de mídias sociais, foi estudado o conceito dos algoritmos de deep learning que contribuem com a análise dos dados não estruturados, geralmente compostos por imagens e textos publicados por usuários nas mídias sociais. Se o algoritmo for treinado, ele poderá reconhecer diversos tipos de elementos nos dados monitorados.

Por fim, os benefícios da inteligência artificial foram estruturados em três tempos do processo de monitoramento de mídias sociais: antes, durante e depois. $\mathrm{O}$ antes contempla a fase de planejamento, que necessita de informações ágeis e organizadas para a elaboração da estra- 
tégia. Nesta fase o poder de generalização das RNAs será benéfico no ponto de vista da velocidade de leitura da informação. $O$ durante está relacionado à interação com os usuários, que pode ser automatizada parcialmente e, por último, o depois é a análise de resultados que pode ser casada com um reconhecimento de linguagem natural a partir dos algoritmos de deep learning, que irá permitir a exploração dos dados a partir de relatórios personalizados.

A inteligência artificial deve ser interpretada sempre como uma solução que irá ampliar a capacidade do ser humano na manipulação de dados e não como um problema no caso de substituir determinados cargos. Em relação a monitoramento de mídias sociais, será sempre mais vantajoso e relevante analisar as informações e tomar decisões com base nos dados do que gastar energia no trabalho operacional do projeto. Conforme a tecnologia avança, os modelos de negócio na área de mídias sociais também evoluem e tornam-se mais estratégicos.

Essa pesquisa pode ser continuada através de um estudo de caso com empresas que utilizam ferramentas avançadas de monitoramento de mídias com aplicação de inteligência artificial. Com este estudo de caso será possível analisar de forma prática o real impacto desta tecnologia nas organizações e o tempo e recursos necessários para obter resultados consistentes.

\section{Referências}

Araujo, R. \& Steimer, D. (2016). Análise da informação. In: Silva, T. \& Stabile, M. Monitoramento e pesquisa em mídias sociais: metodologias, aplicações e inovações. São Paulo, SP: Uva limão.

Burger, L (2017). Perspectivas do cenário digital. ComScore.

Copeland, M. (2016). What's the difference between artificial intelligence, machine learning, and deep learning? NVIDIA.

Datta, S. P. A. (2016). The elusive quest for intelligence in artificial intelligence. Massachusetts Institute of Technology.

Gil, A. C. (2008). Métodos e técnicas de pesquisa social. (6a ed.). São Paulo, SP: Atlas.

Glauner, P. O. \& State, R. (2016) Deep learning concepts from theory to practice. Security and trust Ju. University of Luxembourg.

Goodfellow, I., Bengio, Y. \& Courville, A. (2016). Deep learning. MIT Press.

Lake, B. M., Ullman, T. D., Tenenbaum, J. B., \& Gershman, S. J. (2016). Building machines that learn and think like people. Cornell University.

Lima, I. (2014). Inteligência artificial. (3a ed.). Campus.

Russell, S. \& Norvig, P. (2013). Inteligência artificial. (3a ed), Rio de Janeiro, RJ: Elsevier.

Silva, T. \& Stabile, M. (2016). Monitoramento e pesquisa em mídias sociais: metodologias, aplicações e inovações. São Paulo, SP: Uva limão.

Silva, T. \& Stabile, M. (2012). Para entender o monitoramento de mídias sociais. Bookess. 